\title{
Bilateral entorhinal cortex lesions impair DRL performance in rats
}

\author{
J. J. RAMIREZ, C. MARTIN, M. L. McQUILKIN, K. A. MACDONALD, \\ M. VALBUENA, and J. M. O'CONNELL \\ Davidson College, Davidson, North Carolina
}

\begin{abstract}
The entorhinal cortex participates in a variety of spatial and locomotor behaviors that are thought to be mediated by the hippocampal formation. The present study examined the possibility that the entorhinal area contributes to the maintenance of an operant behavior in which the hippocampus is also implicated-differential reinforcement of low-rate responding (DRL). Rats with bilateral entorhinal cortex lesions or sham operations were tested for retention of a preoperatively learned DRL (10-sec delay) task. Rats with entorhinal lesions were impaired on measures of response rate, temporal discrimination, and response efficiency for 2 to 3 weeks after surgery. Histological analyses indicated that all the rats sustained complete entorhinal lesions. The entorhinal cortex may be an important component of the hippocampal formation contributing to the performance of DRL tasks.
\end{abstract}

The hippocampus has been implicated in a wide variety of cognitive processes, including learning and memory, cognitive mapping, temporal discrimination, and response inhibition (see Chozick, 1983, Isaacson, 1982, and Izquierdo \& Medina, 1993, for review). In recent years numerous investigators (e.g., Brookes, Rawlins, Gray, \& Feldon, 1983; Gauthier, Destrade, \& SoumireuMourat, 1983; Loesche \& Steward, 1977; Olton, Walker, \& Gage, 1978; Olton, Walker, \& Wolf, 1982; Ramirez \& Stein, 1984) have focused their attention on the contribution that several of the hippocampal afferents and efferents make to these cognitive processes. One of the most striking features of the latter studies, perhaps not surprisingly, is the tremendous similarity among the behavioral deficits manifested after damage to each of the primary hippocampal afferents and efferents (e.g., Gray \& McNaughton, 1983; Johnson, Olton, Gage, \& Jenko, 1977; Olton et al., 1982).

Within this context, the entorhinal cortex (EC) is particularly interesting, because it is the major cortical afferent of the hippocampus and dentate gyrus (DG) (Hjorth-Simonsen \& Jeune, 1972; Wyss, 1981). Approximately $90 \%$ of the synapses in the outer two-thirds of the molecular layer of the DG are of entorhinal origin (Steward \& Vinsant, 1983). Entorhinal damage typically produces behavioral impairments reminiscent of hippocampal lesions-for example, open-field locomotor hyperactivity (Fass \& Ramirez, 1984; Lasher \& Steward,

This research was supported by grants from the North Carolina Board of Science and Technology, the National Institute of Mental Health (MH47895), and the National Science Foundation (BNS9020151) to J. J. Ramirez. We wish to thank Antoinette Dyer and C. Allen Sorenson for their helpful comments on the manuscript and Fern Duncan for her help in typing the manuscript. Address correspondence to J. J. Ramirez, Department of Psychology, Davidson College, Davidson, NC 28036 (e-mail: juramirez@davidson.edu).
1981; Ramirez, Fass, Karpiak, \& Steward, 1987; Steward, Loesche, \& Horton, 1977), impaired spatial alternation performance (Loesche \& Steward, 1977; Olton et al., 1978; Ramirez, Fass, Kilfoil, et al., 1987; Ramirez \& Stein, 1984), perseverative behavior (Entingh, 1971; Ramirez, Labbe, \& Stein, 1988), and impaired HebbWilliams maze performance (Stein \& Will, 1983).

One behavioral test that is sensitive to lesions of the hippocampus is the differential reinforcement of lowrate response task (DRL). Simply stated, DRL tasks require that an animal emit a barpress response in an operant chamber, withhold a subsequent barpress response for a specific interval of time (i.e., the interresponse time), and then strike the lever again in order to receive a reinforcement. The DRL task has generally been used as a measure of response inhibition or timing behavior. Numerous studies have demonstrated that lesions of the hippocampus profoundly impair performance on the DRL task, as reflected in the large number of early responses emitted during the interresponse time (IRT) (see Gray \& McNaughton, 1983, and Isaacson, 1982, for review).

Despite the wealth of studies describing entorhinal involvement in open-field activity, spatial behavior, as well as other behaviors, little is presently known about the contribution that the EC may make to DRL behavior. In one previous investigation, Johnson et al. (1977) demonstrated that whereas DRL 20 (i.e., the IRT = $20 \mathrm{sec}$ ) performance was significantly disrupted by total fornix, medial fornix, and septum lesions, EC lesions failed to alter DRL efficiency. Unfortunately, Johnson et al. made lesions restricted to the lateral aspect of the entorhinal area; thus, their lesions may have been too small to produce an impairment in DRL performance. There is evidence that (a) the lateral and the medial aspects of the EC have somewhat dissimilar afferent and efferent projections (see Hjorth-Simonsen \& Jeune, 
1972; Swanson \& Kohler, 1986; Wyss, 1981), and (b) the two areas are known to contribute differentially to the acquisition, retention, and extinction of a continuous reinforcement (CRF) operant schedule (Gauthier et al., 1983). Thus, the lateral and the medial entorhinal cortices are anatomically distinct and they appear to be functionally distinct in CRF training, at the very minimum.

The objective of the present investigation, therefore, was to determine whether bilateral electrolytic lesions of both the medial and lateral aspects of the entorhinal cortex produce impaired DRL performance. We report here that bilateral electrolytic lesions of both the lateral and medial aspects of the entorhinal cortex, along with some injury to the pre- and parasubiculum and subiculum, significantly impair DRL performance for up to 2 to 3 weeks after surgery. Future studies employing selective cytotoxic techniques limiting injury to the medial and lateral aspects of the entorhinal area are needed to gain a more precise understanding of the entorhinal area's putative contribution to DRL performance.

\section{METHOD}

\section{Subjects}

Twenty male Sprague-Dawley rats $(350-400 \mathrm{~g})$, about 90 days old at the start of the experiment, were obtained from Hilltop Lab Animals. The rats were housed in individual cages in a colony room maintained on a 14-h:10-h light:dark cycle. All training and testing was conducted during the light portion of the cycle. The rats were maintained at $95 \%$ of their free-feeding weight on a diet of Purina Lab Chow. The rats had ad-lib access to water. Using an ABBA alternating schedule, we assigned the rats to the lesion or sham control group when they reached the training criterion.

\section{Apparatus}

Behavioral training and testing was conducted in two identical $20 \times 20 \times 23 \mathrm{~cm}$ Skinner boxes (Lafayette Instruments Co.). The two side walls and ceiling were made of clear Plexiglas, and the two end walls were made of aluminum. The floor consisted of steel bars. One end wall contained a lever located $3.5 \mathrm{~cm}$ above the floor and $6.5 \mathrm{~cm}$ left of center. Directly above the lever $(4.5 \mathrm{~cm})$ was a white cue lamp which was illuminated to indicate that the lever was inactive (i.e., before and after the session). Centered on the same wall was a $7.5 \times 6 \mathrm{~cm}$ opening located $2.5 \mathrm{~cm}$ above the floor. The reinforcement was delivered to this opening by the operation of a solenoid-driven water dipper. The reinforcement was a $0.05-\mathrm{ml}$ drop of a $50 \%$ solution of (Eagle Brand) sweetened condensed milk. The Skinner box was located in a sound-attenuating chamber made of plywood. That chamber was ventilated by an electric fan, which also provided masking noise.

The Skinner boxes were connected to a MED Associates interface and Apple IIe computer. The sessions were controlled by computer programs written in a compiled version of Applesoft Basic.

\section{Behavioral Procedure}

Once the rats had been shaped to press the lever, they were put on a fixed ratio 2 schedule for one session. The next day the rats began training on the DRL reinforcement schedule. We used a DRL 10 procedure in which a rat had to make a minimum of two responses for each reinforcement. A 10 -sec delay was chosen because of previous work demonstrating that hippocampectomized rats are impaired on DRL tasks with delays of about this length
(Boitano, Dokla, Mulinski, Misikonis, \& Kaluzynski, 1980). Thus, at the beginning of a session and after each reinforcement, the rat had to press the lever once, wait at least $10 \mathrm{sec}$, then press the lever a second time. Whenever the rat pressed the lever before the $10 \mathrm{sec}$ had elapsed, the clock was reset to 0 so that the rat had to withhold responding for $10 \mathrm{sec}$ from that moment in order to obtain the reinforcement.

Each rat was trained on the schedule until (a) it met the performance criterion of three out of four successive sessions with a temporal discrimination ratio of 0.65 (see below) or (b) it failed to reach criterion after 45 days of training, in which case it was dropped from the study. The rat was assigned to a group and underwent the appropriate surgery on the day after reaching criterion. The rats were allowed 3 days to recover from the surgery and then were placed back on the DRL 10 reinforcement schedule for at least 28 days.

All sessions began with the offset of the cue lamp and continued until the rat had earned 50 reinforcements or $50 \mathrm{~min}$ had passed, whichever occurred first. The end of the session was signaled by the onset of the cue lamp.

\section{Dependent Variables}

DRL schedules produce low rates of responding as well as a distinctive pattern of responding which is characterized by relatively long IRTs. Thus, in addition to response rates, we examined relative frequency histograms of the IRTs using 1 -sec intervals. Because we required two responses per reinforcement, the rats tended to emit bursts of responding, resulting in a high frequency of short IRTs. However, well-trained rats had low frequencies of IRTs between 3 and $9 \mathrm{sec}$ long and increased frequencies of IRTs between 9 and $12 \mathrm{sec}$ long. To capture this aspect of the histogram, we computed "temporal" discrimination ratios of the form $A /(A+B)$ where $A$ and $B$ represent the number of IRTs with a length of 9.0-11.9 sec and 6.0-8.9 sec, respectively. On the basis of a pilot study, we decided that a ratio of 0.65 reflected adequate performance on the DRL task. In addition, rate of responding (responses/minute) and an efficiency ratio [reinforced responses/ (total response - initiating responses)] were computed. Because there was considerable variability in the response rates prior to surgery, the rate data for postsurgery days were normalized by dividing by each rat's average rate during the last 5 days of baseline. All within-subject comparisons were made using Wilcoxon signed rank tests, while between-groups comparisons were made using Wilcoxon rank sum tests (Hollander \& Wolfe, 1973).

\section{Surgical Procedure}

The rats were injected intraperitoneally with $0.1 \mathrm{ml}$ atropine sulfate followed by sodium pentobarbital (Nembutal, $50 \mathrm{mg} / \mathrm{kg}$ ) anesthetic. Bilateral electrolytic lesions of the EC (1.0 mA for $45 \mathrm{sec}$ at each of nine locations) were made under aseptic conditions by lowering an electrode to the stereotaxic coordinates described by Loesche and Steward (1977) $(1.5 \mathrm{~mm}$ anterior to the transverse sinus; 3,4 , and $5 \mathrm{~mm}$ lateral to the sagittal sinus; 2,4 , and $6 \mathrm{~mm}$ ventral to dura). Animals that received sham surgery were treated similarly, with the exception of the electrode penetration into the brain.

\section{Histology}

At the termination of testing, the rats were deeply anesthetized with Nembutal and perfused transcardially with physiological saline $(0.9 \%)$ followed by $10 \%$ buffered formalin. The brains were removed and postfixed in $10 \%$ formalin for $48 \mathrm{~h}$; they were then cryoprotected overnight in a solution of $30 \%$ sucrose-formalin. The brains were frozen and sectioned in $30-\mu \mathrm{m}$-thick horizontal sections. Every sixth section was stained with cresyl violet acetate. Finally, lesion reconstructions were sketched using schematics in Paxinos and Watson (1986). 


\section{RESULTS}

\section{Behavior}

Eleven of the 20 rats reached criterion during the experiment, with 5 and 6 rats having been assigned to the lesion and sham groups, respectively. The average number of days to criterion was 26.5 (24.4 for the lesion group and 28.2 days for the sham group), with a range of 18-39 days. Over the last 5 training days, the lesioned animals had a mean response rate of 6.5 , which was not significantly different from the sham animals' mean of 5.9. The mean efficiency ratios were .35 and .38 for the lesion and sham groups, respectively. The mean discrimination ratios of the two groups also were not statistically different.

The performance in the DRL task was severely disrupted by the entorhinal cortex lesions, but not by the sham surgery. This result is shown by a comparison of the relative frequency distributions of IRTs from the last day of training and the first test day after the operation (Postoperative Day 4) which are shown in Figure 1. The two groups had very similar patterns prior to surgery, with a relatively low frequency of IRTs in the 3-9 sec range and increased frequency of IRTs in the 9-12 sec range. The sham rats maintained this pattern after
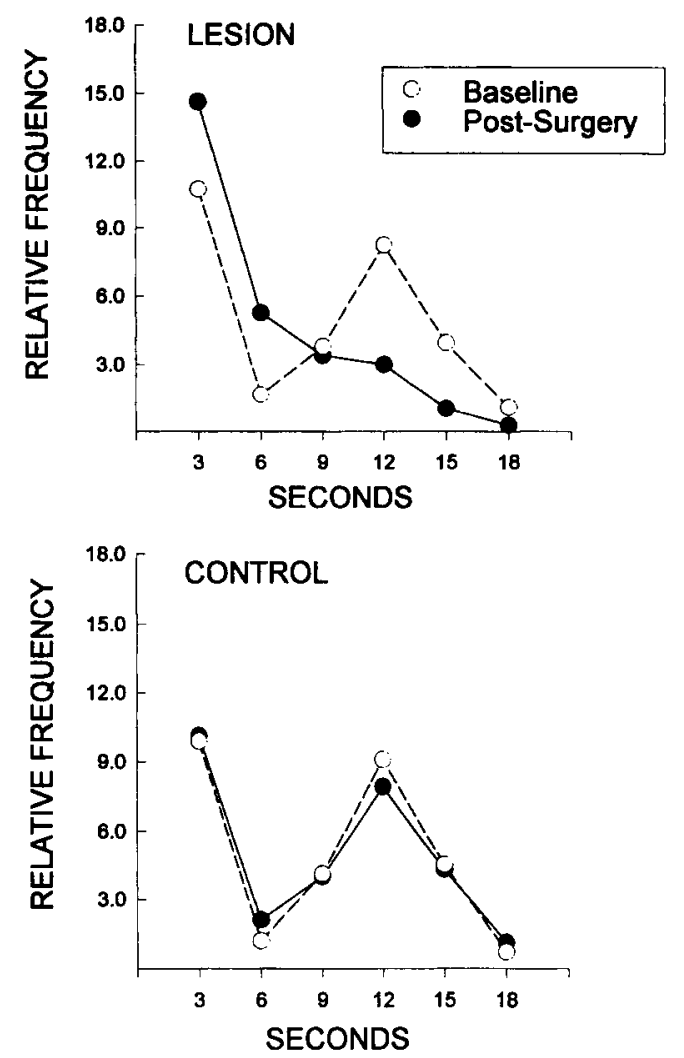

Figure 1. Relative frequency distributions of interresponse times (IRTs) on the last day of training (baseline) and the first session after surgery (Day 4 PS). Each value on the $x$-axis represents the upper limit of the interval beginning with the time just preceding it-for example, 0 to $3 \mathrm{sec}, 3$ to $6 \mathrm{sec}$, and so forth.
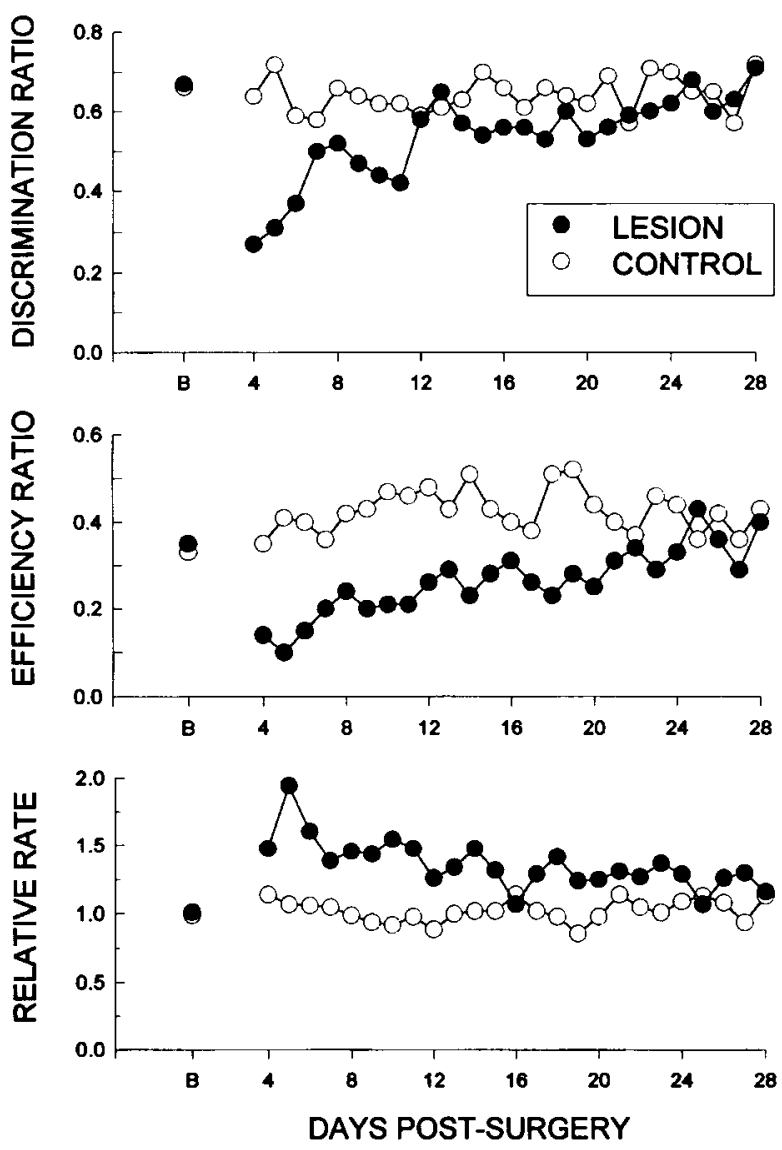

Figure 2. Three measures of performance are shown during the last 5 days of training $(B=$ baseline) and as a function of days postsurgery for the lesion $(N=5)$ and the sham control $(N=6)$ groups.

surgery. However, the rats that had undergone entorhinal lesions displayed a monotonic distribution of IRTs that was heavily skewed toward the low end, indicating that these rats responded vigorously at short IRTs and thus were less able to withhold responding for $10 \mathrm{sec}$.

Mean discrimination ratios as a function of days postsurgery are shown in the top panel of Figure 2. This measure, which reflects the important feature of the IRT histograms shown in Figure 1, shows that the performance deficit displayed by the lesion group persisted for several days but did recover within 2 weeks of surgery. The performance of the control animals was not disturbed by the sham surgery; their mean discrimination ratio remained well above 0.5 . In fact, the withinsubjects comparison of ratios on the last day of baseline and Day 4 postsurgery shows a significant decrease for the lesion group $(T+=15, p=.031)$ but no difference for the control group $(T+=16, p=.156)$. Furthermore, differences between the discrimination ratios for the two groups were statistically significant $\left(W_{\mathrm{S}} \geq 40\right.$, $p s<.05$ ) on Days $4,5,6,10$, and 11 postsurgery.

The performance deficit in the lesioned rats was also exhibited in decreased efficiency ratios and increased response rates in these animals (shown in the middle 

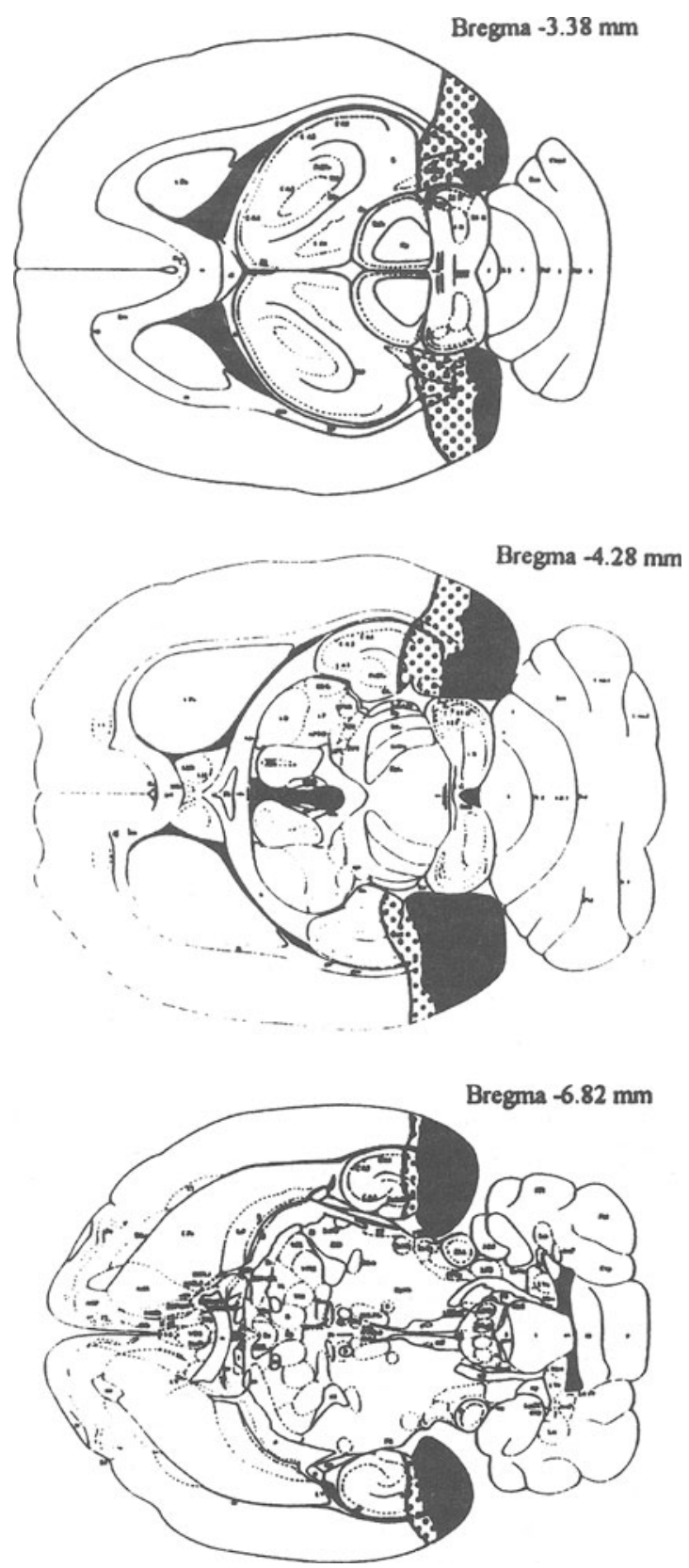

Figure 3. Reconstructions of the minimum and maximum extents of EC lesions represented in three horizontal schematics from dorsal (bregma $-3.38 \mathrm{~mm}$ ) to ventral (bregma $-6.82 \mathrm{~mm}$ ) levels (from Paxinos \& Watson, 1986). The dotted areas indicate the largest lesions; the black areas indicate the smallest lesions. Please note that both medial as well as lateral aspects of $\mathrm{EC}$ were damaged.

and bottom panels of Figure 2). The response rates and efficiency ratios of the lesioned rats showed some improvement over days, although their performance on these measures remained poorer than that of the control groups through Day 20 . The difference in the normalized response rates between the groups was statistically significant on Days 5, 6, 9, 10,11, 14, and 19. The dif- ference in efficiency ratios was significant on Days 4,5 , $6,7,9,10,11,12,14,18,19$, and 20 .

\section{Anatomy}

Histological analyses indicated that both aspects of the entorhinal area were extensively damaged, particularly layers II and III of EC, which contain the cells of origin of the inputs to DG and hippocampus proper (Steward \& Scoville, 1976; Steward \& Vinsant, 1978). The damage encroached on the subiculum and the dentate gyrus in the more ventral regions, but the hippocampus and dentate gyrus were spared dorsally (see Figure 3).

\section{DISCUSSION}

In contrast to previous reports (discussed in Chozick, 1983, and Johnson et al., 1977), our results indicate that the entorhinal cortex plays a significant role in DRL behavior. Despite the fact that we employed a delay of only $10 \mathrm{sec}$ (Johnson et al., 1977, used a 20-sec delay), rats with bilateral entorhinal lesions were impaired on the DRL task, as revealed by three separate measures of performance. One of those measures-the discrimination ratio-indicated near complete recovery of function within 2 weeks postsurgery. A second and third measure - response rate and efficiency ratio-showed substantial recovery during the final week of testing. This difference among the performance measures may be due to the different aspects of behavior that are quantified in each measure. For example, the efficiency measure would be particularly sensitive to increases in response bursts - a series of responses with short IRTs - whereas, the discrimination ratio would be unaffected by this aspect of behavior. These results are supported by earlier preliminary reports suggesting a possible entorhinal contribution to DRL behavior (Isaac, Nonneman, \& Scheff, 1987; Ramirez et al., 1990). Recently, Harrigan, Peredery, and Persinger (1990) reported that lithiumand pilocarpine-induced limbic seizures in rats produce deficits on DRL 6 and DRL 12 tasks, which may result from the extensive injury to the entorhinal cortex observed in these preparations.

Although the design of the present study makes it difficult to pinpoint with absolute certainty which of the three variables we manipulated (i.e., the length of the delay, the start of postoperative testing, and size of the lesion) was responsible for the emergence of the DRL impairment, we believe that the extent of the entorhinal lesions, which include the medial and lateral EC, was the most salient factor. Neither a shorter postoperative recovery period alone nor a DRL delay half the length of that used by Johnson et al. (1977) are likely to have been primarily responsible for the impairment in DRL performance. Preliminary reports published in abstract form from our laboratory (Ramirez et al., 1990) and that of Isaac et al. (1987) indicate that rats sustaining total entorhinal injury and tested for retention of a DRL 20 
task (as that used by Johnson and his colleagues) produce persistent deficits lasting more than 1 month after surgery. Because the rats in the present study recovered 2-3 weeks after surgery, it appears likely that the $10-\mathrm{sec}$ IRT we used, if anything, may have contributed to the recovery from the DRL impairments. Our findings are consistent with the fact that rats with extensive hippocampal lesions are only moderately impaired in their ability to acquire DRL tasks with 8-12 sec delays (Boitano et al., 1980; Rawlins, Winocur, \& Gray, 1983).

Whereas rats with lateral EC injury were unimpaired at the start of testing 2 weeks postoperatively in Johnson et al.'s (1977) study, rats with total EC damage tested within 3 days of surgery in our study were impaired on the DRL task for 2-3 weeks. Johnson et al. may have failed to observe a DRL impairment in their rats with EC injury because the entorhinal lesions were small, which excluded the medial aspect. It is of interest that results from studies of spontaneous alternation in rats are similar to those reported here: Whereas lateral EC lesions fail to produce an impairment on spontaneous alternation (Johnson et al., 1977), complete bilateral EC lesions produce a persistent spontaneous alternation deficit (Scheff \& Cotman, 1977).

One interpretation of Johnson et al.'s (1977) findings is that the lateral EC, specifically, contributes little to either DRL performance or spatial behavior. As Gauthier et al. (1983) have proposed, the entorhinal cortex may not be functionally homogeneous. Since Scheff and Cotman (1977), Johnson et al. (1977), and we did not restrict the lesions used in our investigations to the medial EC, the possibility that the medial aspect of the entorhinal area contributes uniquely to DRL and/or spatial alternation performance remains to be examined.

It is intriguing to note that the brain-injured rats tested on a DRL 10 task recovered (a) on the discrimination ratio within a time course that parallels sprouting in the hippocampus (see Cotman \& Nadler, 1978, for a review), and (b) on the efficiency ratio and relative rate measurements only after the time at which the synaptic profiles of reinnervated granule cell dendrites are mature and capable of supporting long-term potentiation (Reeves \& Steward, 1986). Further studies are necessary to determine whether the recovery observed when a 10 -sec delay is used may be related to hippocampal sprouting or be dependent on task experience.

As to the nature of the lesion-induced deficits, our data show that rats with entorhinal injury suffered from an impairment characterized by response bursts and an inability to discriminate temporally on a DRL 10 task during the first 3 weeks after surgery. The behavioral impairment, therefore, was not simply an inability to press the lever. Rather, once a rat with entorhinal injury had initiated a barpress, it continued the response pattern at high rates with short IRTs - the same behavioral pattern observed after hippocampal injury (Gray \& McNaughton, 1983; Isaacson, 1982). In addition, although the occipital cortex overlying the entorhinal area sustained damage, the animals exhibited little difficulty in finding the manipulanda. Their performance on the rates of response and the discrimination ratios indicate that they were capable of locating and responding to the lever immediately after the start of the delay period as early as Day 1 postsurgery. Moreover, it is unlikely that the behavioral impairments result from a nonspecific, mass action effect. Extensive orbitofrontal, medial frontal, and posterior parietal cortex lesions fail to produce impairments in DRL responding similar to those observed in the entorhinectomized rats of the present study (Finger et al., 1987; Kolb, Nonneman, \& Singh, 1974; Nonneman, Voight, \& Kolb, 1974; Woodruff, Baisden, Whittington, \& Benson, 1987), if at all.

Because our lesions extended into the subiculum and the ventralmost posterior hippocampus, the possibility exists that the involvement of these structures contributed to the DRL impairments. However, neither the interruption of hippocampal-subiculum projections by aspiration or thermocoagulation (Jarrard \& Becker, 1977) nor the neurotoxic lesioning of the subiculum itself with ibotenic acid (Sinden, Rawlins, Gray, \& Jarrard, 1986) produces an impairment in the acquisition of DRL 12, DRL 18, or DRL 20 tasks. Although whether DRL acquisition per se is affected by entorhinal damage has yet to be determined, these findings suggest the prospect that the subicular contribution to DRL performance is minimal; however, we are unable to rule out the possibility that the pre- and parasubiculum may also be playing some role in DRL performance since our lesions impinged on these structures to some extent in all our subjects. As for hippocampal involvement, extensive posterior hippocampus lesions do not impair retention of a DRL 20 task (Johnson et al., 1977). Our results, therefore, are consistent with the hypothesis that combined lesions of the medial and lateral aspects of the entorhinal area were principally responsible for the disruption of DRL behavior in the present experiment. As recent work has demonstrated (Bouffard \& Jarrard, 1988; Dunn \& Everitt, 1988), however, some caution should be exercised when extrapolating from studies using electrolytic lesions to assess structure-function relationships in the CNS. The possible involvement of fibers-ofpassage in the lesion area may contribute to some of the behavioral alterations attributed to the target structure. Thus, future studies using neurotoxic techniques precisely limited to the entorhinal cortex to examine the role of the entorhinal area in DRL would be valuable.

On the basis of their findings, Johnson et al. (1977) proposed a functional distinction between the anterior (i.e., anterodorsal hippocampus, fornix, and septal connections) and posterior (i.e., entorhinal cortex and posteroventral hippocampus) hippocampal systems. They suggested that the posterior connections of the hippocampal system make a minimal contribution to the support of either DRL or spatial alternation behavior. Considering our present results and those of Scheff and Cotman (1977), it would appear that the entorhinal cortex, rather, contributes to both DRL and spatial alternation behavior. Thus, dividing the hippocampal system into 
functional anterior and posterior compartments may not reveal the complex nature of the cooperative or complementary interactions among its components that ultimately underlie learning and memory.

The complexity of these interactions is reflected in one body of evidence indicating that the hippocampus and the entorhinal cortex appear to be functionally dissociated and another indicating a cooperative interaction. Jarrard (1993) recently postulated that the functions of these two structures are dissociable along dimensions of spatial memory: the hippocampus is intimately involved in the processing of spatial information; whereas the entorhinal cortex may contribute disproportionately to nonspatial memory. Investigations conducted recently indicate that the entorhinal area's contribution to the acquisition of certain nonspatial tasks, for example, object recognition, and delayed nonmatch to sample (Hagan, Verheijck, Spigt, \& Ruigt, 1992; Jarrard, 1993; Otto \& Eichenbaum, 1992) may be more prominent than that of the hippocampus. Although both the hippocampus and the amygdala have been the focus of research into amnesia following temporal lobe injury in humans and monkeys, Squire and Zola-Morgan (1991), Zola-Morgan, Squire, and Amaral (1989), ZolaMorgan, Squire, Amaral, and Suzuki (1989), and ZolaMorgan, Squire, Clower, and Rempel (1993) have provided evidence that the parahippocampal and perirhinal cortices, structures which funnel about $60 \%$ of the input to the entorhinal cortex, may play as fundamental a role on delayed nonmatch to sample and delayed retention of object discrimination tasks as the hippocampus. It appears that the amygdaloid contribution to learning and memory may be less significant than previously believed. Potentially of greater import, Clower, AlvarezRoyo, Zola-Morgan, and Squire (1991) have described in a preliminary report that selective lesions of the hippocampus produce milder deficits on delayed retention of easy object discrimination and concurrent object discrimination than do lesions that include the hippocampus, parahippocampal cortex, and posterior entorhinal cortex. Thus, the cortex adjacent to the hippocampus may underlie at least some of the memory processing often attributed to the hippocampus.

Although the entorhinal cortex may, indeed, uniquely contribute to learning and memory on certain spatial and nonspatial memory tasks, the two structures appear to cooperate on processes contributing to behavioral flexibility. An impairment common to the behavior of both hippocampectomized and entorhinectomized rats on a variety of spatial and nonspatial tasks is an apparent inability to inhibit responses once they have been initiated (see Isaacson, 1982, for a review of the hippocampal literature). The DRL deficit following hippocampal lesions and our present observation of a similar deficit in rats with entorhinal lesions may be interpreted as an impairment in response inhibition-although a more detailed analysis of the DRL requirement is necessary to reveal how closely the impairments after EC lesions parallel those following hippocampal lesions.
Our present findings, taken together with our earlier preliminary results (Ramirez et al., 1990) and those of Isaac et al. (1987), indicate that as the DRL requirement increases from DRL 10 to DRL 20, the extent of the behavioral impairment after entorhinal lesions also increases. Previously, Sinden et al. (1986) demonstrated that although complete ibotenic acid-induced lesions of the hippocampus only mildly impair DRL 12 performance, these lesions seriously disrupt DRL 18 performance - a finding similar to that reported by Boitano et al. (1980). It is possible therefore that the two structures cooperate on DRL tasks and the absence of either is sufficient to compromise the processing of information required for adequate task efficiency.

Recent work by Izquierdo and his associates underscores the potential cooperative nature of the entorhinal cortex and the hippocampus on a step-down avoidance task (Ferreira, Da Silva, Medina, \& Izquierdo, 1992; Ferreira, Wolfman, et al., 1992; Izquierdo, Da Silva, Bueno e Silva, Quillfeldt, \& Medina, 1993; Jerusalinsky et al., 1992; Willner et al., 1993). Posttraining infusion of the glutamatergic antagonists aminophosphonopentanoic acid (AP5) and cyanonitroquinoxalinedione (CNQX), or the gamma-amino butyric type $\mathrm{A}\left(\mathrm{GABA}_{\mathrm{A}}\right)$ agonist muscimol into the entorhinal cortex severely disrupts retention performance on passive avoidance conditioning similar to that observed after intrahippocampal injections of these agents. The entorhinal contribution, however, appears to be critical at both the time of acquisition as well as at a time point significantly later $(90$ or $180 \mathrm{~min}$ ) than either the hippocampus or the amygdala (Willner et al., 1993).

In addition to the debilitative effects on DRL and passive avoidance tasks, disrupting entorhinal functioning increases responding on operant conditioning (Gauthier et al., 1983; Gauthier \& Soumireu-Mourat, 1981), increases locomotor activity in an open field (Fass, 1983; Fass \& Ramirez, 1984; Lasher \& Steward, 1981; Ramirez, Fass, Karpiak, \& Steward, 1987; Steward et al., 1977), and produces perseverative behavior in a maze (Loesche \& Steward, 1977; Ramirez et al., 1991; Ramirez et al., 1988; Ramirez \& Stein, 1984; Stein \& Will, 1983) in ways reminiscent of hippocampal injury (Gray \& McNaughton, 1983; Jarrard \& Becker, 1977; Shull \& Holloway, 1985; Olton et al., 1978; and, for a review, Isaacson, 1982).

Collectively, our findings and those described above indicate that although some memory processes may be unique to either the hippocampus or the entorhinal cortex, other fundamental processes such as those involved in response inhibition may be shared by these two structures. Specific contributions aside, the entorhinal cortex is now emerging as a critical component in our conceptualization of the neural substrate underlying learning and memory. The entorhinal area's widespread reciprocal connections with the hippocampus (Hjorth-Simonsen \& Jeune, 1972; Witter, Groenewegen, Lopes da Silva, \& Lohman, 1989; Wyss, 1981) and the cortical mantle (Swanson \& Kohler, 1986) place it in a unique and pivotal position for modulating and relaying information 
between the hippocampus and the neocortex. The attractiveness of these neuroanatomical considerations notwithstanding, the extent of the cooperative and/or complementary nature of the relationship between the entorhinal cortex and the hippocampus in their contributions to learning and memory remains to be fully explored.

\section{REFERENCES}

Boitano, J. J., Dokla, C. P. J., Mulinski, P., Misikonis, S., \& KALUZYNSKI, T. (1980). Effects of hippocampectomy in an incremental-step DRL paradigm. Physiology \& Behavior, 25, 273-278.

Bouffard, J. P., \& JaRRaRd, L. E. (1988). Acquisition of a complex place task in rats with selective ibotenate lesions of hippocampal formation: Combined lesions of subiculum and entorhinal cortex versus hippocampus. Behavioral Neuroscience, 102, 828-834.

Brookes, S., Rawlins, J. N. P., Gray, J. A., \& Feldon, J. (1983). DRL performance in rats with medial or lateral septal lesions. Physiological Psychology, 11, 178-184.

CHozick, B. S. (1983). The behavioral effects of lesions of the hippocampus: A review. International Journal of Neuroscience, 22. 63-80.

Clower, R. P., Alvarez-Royo, P., Zola-Morgan, S., \& Souire, L. R. (1991, November). Recognition memory impairment in monkeys with selective hippocampal lesions. Paper presented at the annual meeting of the Society for Neuroscience, New Orleans.

Cotman, C. W., \& NadLer, J. V. (1978). Reactive synaptogenesis in the hippocampus. In C. W. Cotman (Ed.), Neuronal plasticity (pp. 227-271). New York: Raven Press.

Dunn, L. T., \& Everitt, B. J. (1988). Double dissociations of the effects of amygdala and insular cortex lesions on conditioned taste aversion, passive avoidance, and neophobia in the rat using the excitotoxin ibotenic acid. Behavioral Neuroscience, 102, 3-23.

ENTINGH, D. (1971). Perseverative responding and hyperphagia following entorhinal lesions in cat. Journal of Comparative \& Physiological Psychology, 75, 50-58.

FAss, B. (1983). Temporal changes in open-field activity following progressive lesions of entorhinal cortex: Evidence for enhanced recovery. Behavioral \& Neural Biology, 37, 108-124.

FASS, B., \& RAMIREZ, J. J. (1984). Effects of ganglioside treatments on lesion-induced behavioral impairments and sprouting in the CNS. Journal of Neuroscience Research, 12, 445-458.

Ferreira, M. B. C., Da Silva, R. C., Medina, J. H., \& Izquierdo, I. (1992). Late posttraining memory processing by entorhinal cortex: Involvement of NMDA and GABAergic receptors. Pharmacology, Biochemistry \& Behavior, 41, 767-771.

Ferreira, M. B. C., Wolfman, C., Walz, R., Da Silva, R. C., ZanatTa, M. S., Medina, J. H., \& IzQuierdo, I. (1992). NMDAdependent, GABA-A-sensitive role of the entorhinal cortex in posttraining memory processing. Behavioural Pharmacology, 3, 387394.

Finger, S., Altemus, K. L., Green, L., Wolf, C., Miller, J., \& ALMLI, C. R. (1987). Effects of medial frontal cortex lesions on DRL performance in rats. Physiology \& Behavior, 41, 387-389.

Gauthier, M., Destrade, C., \& Soumireu-Mourat, B. (1983). Functional dissociation between lateral and medial entorhinal cortex memory processes in mice. Behavioral Brain Research, 9, 111-117.

Gauthier, M., \& Soumireu-Mourat, B. (1981). Behavioral effects of bilateral entorhinal cortex lesions in the Balb/c mouse. Behavioral \& Neural Biology, 33, 419-436.

GRAY, J. A., \& MCNAUGHTON, N. (1983). Comparison between the behavioural effects of septal and hippocampal lesions: A review. Neuroscience \& Biobehavioral Reviews, 7, 119-188.

Hagan, J. J., VerheiJck, E. E., Spigt, M. H., \& Ruigt, G. S. F. (1992). Behavioural and electrophysiological studies of entorhinal cortex lesions in the rat. Physiology \& Behavior, 51, 255-266.

Harrigan, T., Peredery, O., \& Persinger, M. A. (1990). Failure to acquire an inhibitory task following seizure-induced brain damage. Perceptual \& Motor Skills, 70, 268-270.
HJorth-Simonsen, A., \& Jeune, B. (1972). Origin and termination of the hippocampal perforant path in the rat studied by silver impregnation. Journal of Comparative Neurology, 144, 215-232.

Hollander, M., \& WolfE, D. A. (1973). Nonparametric statistical methods. New York: Wiley.

IsaAC, W. L., Nonneman, A. J., \& Scheff, S. W. (1987, November). Entorhinal lesions, sprouting and behavioral recovery. Paper presented at the annual meeting of the Society for Neuroscience, New Orleans.

IsAaCsON, R. L. (1982). The limbic system. New York: Plenum.

Izquierdo, I., Da Silva, R. C., Bueno E Silva, M., Quillfeldt, J. A., \& MedinA, J. H. (1993). Memory expression of habituation and of inhibitory avoidance is blocked by CNQX infused into the entorhinal cortex. Behavioral \& Neural Biology, 60, 5-8.

IzQuiERDo, I., \& MEdina, J. H. (1993). Role of the amygdala, hippocampus and entorhinal cortex in memory consolidation and expression. Brazilian Journal of Medical \& Biological Research, 26, 573589

JARRARD, L. E. (1993). On the role of the hippocampus in learning and memory in the rat. Behavioral \& Neural Biology, 60, 9-26.

JARRARD, L. E., \& BECKER, J. T. (1977). The effects of selective hippocampal lesions on DRL behavior in rats. Behavioral Biology, 21, 393-404.

Jerusalinsky, D., Ferreira, M. B. C., Walz, R., Da Silva, R. C., Bianchin, M., Ruschel, A. C., Zanatta, M. S., Medina, J. H., \& IZQUIERDO, I. (1992). Amnesia by post-training infusion of glutamate receptor antagonists into the amygdala, hippocampus, and entorhinal cortex. Behavioral \& Neural Biology, 58, 76-80.

Johnson, C. T., Olton, D. S., Gage, F. H., \& Jenko, P. G. (1977). Damage to hippocampus and hippocampal connections: Effects on DRL and spontaneous alternation. Journal of Comparative \& Physiological Psychology, 91, 508-522.

Kolb, B., Nonneman, A. J., \& Singh, R. K. (1974). Double dissociation of spatial impairments and perseveration following selective prefrontal lesions in rats. Journal of Comparative \& Physiological Psychology, 87, 772-780.

Lasher, S. S., \& STEWARD, O. (1981). The time course of changes in open field activity following bilateral entorhinal lesions in rats and cats. Behavioral \& Neural Biology, 32, 1-20.

Loesche, J., \& STEWARd, O. (1977). Behavioral correlates of denervation and reinnervation of the hippocampal formation in the rat: Recovery of alternation performance following unilateral entorhinal cortex lesions. Brain Research Bulletin, 2, 31-39.

Nonneman, A. J., Volght, J., \& KolB, B. (1974). Comparisons of behavioral effects of hippocampal and prefrontal cortex lesions in the rat. Journal of Comparative \& Physiological Psychology, 87, 249-260.

Olton, D. S., Walker, J. A., \& Gage, F. H. (1978). Hippocampal connections and spatial discrimination. Brain Research, 139, 295-308.

Olton, D. S., WALKER, J. A., \& Wolf, W. A. (1982). A disconnection analysis of hippocampal function. Brain Research, 233, 241-253.

Otto, T., \& Eichenbaum, H. (1992). Complementary roles of orbital prefrontal cortex and the hippocampal system in an odor-guided delayed nonmatching to sample task. Behavioral Neuroscience, 106, $762-775$.

Paxinos, G., \& Watson, C. (1986). The rat brain in stereotaxic coordinates. New York: Academic Press.

Ramirez, J. J., Fass, B., KarPIaK, S. E., \& Steward, O. (1987). Effects of exogenous gangliosides on changes in open-field activity after bilateral lesions of the entorhinal cortex. Neuroscience Letters, 75 , 283-287.

Ramirez, J. J., Fass-Holmes, B., Karpiak, S. E., Harshbarger, R., Zengel, D., Wright, P., \& Valbuena, M. (1991). Enhanced recovery of learned alternation in ganglioside-treated rats after unilateral entorhinal cortex lesions. Behavioral Brain Research, 43, 99-101.

Ramirez, J. J., Fass-Holmes, B., Karpiak, S., Tuite, C., AlexanDER, C., \& GREWAL, A. (1990, October). GM1-enhanced recovery of $D R L-20$ and open field activity after bilateral entorhinal cortex lesions in rats. Paper presented at the annual meeting of the Society for Neuroscience, St. Louis, MO. 
Ramirez, J. J., Fass, B., Kilfoll, T., Henschel, B., Grones, W., \& KARPIAK, S. E. (1987). Ganglioside administration reduces behavioral deficits after bilateral entorhinal cortex lesions in rats. Brain Research, 414, 85-90.

Ramirez, J. J., Labbe, R., \& Stein, D. G. (1988). Recovery from perseverative behavior after entorhinal cortex lesions in rats. Brain Research, 459, 153-156.

RAmirez, J. J., \& STEIN, D. G. (1984). Sparing and recovery of alternation performance after entorhinal cortex lesions in rats. Behavioral Brain Research, 13, 55-61.

Rawlins, J. N. P., Winocur, G., \& Gray, J. A. (1983). The hippocampus, collateral behavior, and timing. Behavioral Neuroscience, 97, 857-872.

REEVES, T. M., \& STEWARD, O. (1986). Emergence of the capacity for LTP during reinnervation of the dentate gyrus: Evidence that abnormally shaped spines can mediate LTP. Experimental Brain Research, 65, 167-175.

SCheFF, S. W., \& Cotman, C. W. (1977). Recovery of spontaneous alternation following lesions of the entorhinal cortex in adult rats: Possible correlation to axon sprouting. Behavioral Biology, 21, 286293.

Shull, R. N., \& Holloway, F. A. (1985). Behavioral effects of hippocampal system lesions on rats in an operant paradigm. Brain Research Bulletin, 14, 315-322.

Sinden, J. D., Rawlins, J. N. P., Gray, J. A., \& JarRaRd, L. E. (1986). Selective cytotoxic lesions of the hippocampal formation and DRL performance in rats. Behavioral Neuroscience, 3, 320-329.

Squire, L. R., \& Zola-Morgan, S. (1991). The medial temporal lobe memory system. Science, 253, 1380-1386.

StEIN, D. G., \& WiLL, B. E. (1983). Nerve growth factor produces a temporary facilitation of recovery from entorhinal cortex lesions. Brain Research, 261, 127-131.

StEWARD, O., LOESCHE, J., \& HORTON, W. C. (1977). Behavioral correlates of denervation and reinnervation of the hippocampal formation of the rat: Open field activity and cue utilization following bilateral entorhinal cortex lesions. Brain Research Bulletin, 2, 41-48.

StEWARD, O., \& SCOville, S. A. (1976). Cells of origin of entorhinal cortical afferents to the hippocampus and fascia dentata of the rat. Journal of Comparative Neurology, 169, 347-370.

STEWARD, O., \& VINSANT, S. L. (1978). Identification of the cells of origin of a central pathway which sprouts following lesions in mature rats. Brain Research, 147, 223-244.

StEWARD, O., \& VINSANT, S. (1983). The process of reinnervation in the dentate gyrus of the adult rat: A quantitative electron microscopic analysis of terminal proliferation and reactive synaptogenesis. Journal of Comparative Neurology, 214, 370-386.

Swanson, L. W., \& KoHLER, C. (1986). Anatomical evidence for direct projections from the entorhinal area to the entire cortical manthe in the rat. Journal of Neuroscience, 6, 3010-3023.

Willner, P., Bianchin, M., Walz, R., Bueno e Silva, M., Zanatta, M. S., \& Izquierdo, I. (1993). Muscimol infused into the entorhinal cortex prior to training blocks the involvement of this area in post-training memory processing. Behavioural Pharmacology, 4, 95-99.

Witter, M. P., Groenewegen, H. J., Lopes da Silva, F. H., \& Lohman, A. H. M. (1989). Functional organization of the extrinsic and intrinsic circuitry of the parahippocampal region. Progress in Neurobiology, 33, 161-253.

Woodruff, M. L., Baisden, R. H., WhitTington, D. L., \& Benson, A. E. (1987). Embryonic hippocampal grafts ameliorate the deficit in DRL acquisition produced by hippocampectomy. Brain Research, 408, 97-117.

Wyss, J. M. (1981). An autoradiographic study of the efferent connections of the entorhinal cortex in the rat. Journal of Comparative Neurology, 199, 495-512.

Zola-Morgan, S., Squire, L. R., \& Amaral, D. G. (1989). Lesions of the amygdala that spare adjacent cortical regions do not impair memory or exacerbate the impairment following lesions of the hippocampal formation. Journal of Neuroscience, 9, 1922-1936.

Zola-Morgan, S., Squire, L. R., Amaral, D. G., \& Suzuki, W. (1989). Lesions of perirhinal and parahippocampal cortex that spare the amygdala and hippocampal formation produce severe memory impairment. Journal of Neuroscience, 9, 4355-4370.

Zola-Morgan, S., Squire, L. R., Clower, R. P., \& Rempel, N. L. (1993). Damage to the perirhinal cortex exacerbates memory impairment following lesions to the hippocampal formation. Journal of Neuroscience, 13, 251-265.

(Manuscript received December 2, 1993. revision accepted for publication December 8,1994 .) 